\title{
EDITORIAL
}

\section{The putative role of isoprostanes in human cardiovascular physiology and disease: following the fingerprints}

\section{J-L Cracowski}

Heart 2003;89:821-822

Are isoprostanes more than physiopathological biomarkers of lipid peroxidation? Could they play a role in human cardiovascular physiology and disease?

lisin oprostanes are arachidonic acid metabolites produced through a free radical dependent mechanism. ${ }^{1}$ They are formed in situ on phospholipids, at sites of free radical generation. Once released from cell membranes by phospholipases, isoprostanes circulate in the plasma in free form, and are potentially available for agonist receptor interaction.

Increased formation of isoprostanes was first described in cigarette smokers. ${ }^{2}$ Since this study, their increased formation has been observed in a large number of diseases including atherosclerosis and coronary heart disease. ${ }^{3}$ Some reports also showed that isoprostanes concentrations were increased in the pericardial fluid and urine of patients suffering from heart failure..$^{4-6}$ Isoprostane concentrations increased with the functional severity of heart failure. The study by NonakaSarukawa and colleagues in this issue of Heart further supports the hypothesis that oxidative stress, assessed by urinary $15-\mathrm{F}_{2 \mathrm{t}}$-isoprostane concentrations, is increased in patients with congestive heart failure and correlates with the severity of the disease. ${ }^{7}$ They showed that $15-\mathrm{F}_{2 \mathrm{t}}$-isoprostane values decreased in the 14 days following hospital admission. Interestingly, $15-\mathrm{F}_{2 \mathrm{t}}$-isoprostane values were correlated with plasma B type natriuretic peptide (BNP). These data raise an important issue: in addition to being a pathophysiological marker of oxidative injury, the quantification of $\mathrm{F}_{2}$-isoprostanes might represent a prognostic marker in heart failure-that is, a marker of morbidity, as suggested by the authors. However, no clinical studies aimed at testing isoprostanes as a prognostic marker, with strong end points such as mortality or morbidity, are available in heart failure as well as other cardiovascular diseases.

\section{ROLE OF ISOPROSTANES IN} CARDIOVASCULAR DISEASE

In vitro, $\mathrm{F}_{2}$-isoprostanes induce vasoconstriction and mitogenesis, and stimulate endothelial cells to bind monocytes, one of the key initial events in atherogenesis. Another important and still unresolved enigma is to determine whether isoprostanes are more than simply a biomarker of lipid peroxidation - that is, do isoprostanes play a role in human cardiovascular physiology and disease? The major problem we face is that no specific inhibition of $15-\mathrm{F}_{2 \mathrm{t}}$-isoprostane (or other isoprostanes) can currently be achieved. Belhassen and colleagues ${ }^{8}$ recently showed that S18886, a TP-receptor antagonist, improved both acetylcholine and flow mediated vasodilation in patients suffering from coronary artery disease (CAD) treated with aspirin ( $100 \mathrm{mg} /$ day). This study suggests that TP-receptor agonists other than platelet derived thromboxane $\mathrm{A}_{2}$ are implicated in blood flow regulation, at least in patients with CAD. Similar data on healthy subjects would strengthen the hypothesis that such compounds play a role in vascular physiology. The main and appealing hypothesis raised by the authors is that isoprostanes could be a candidate. The same TP receptor antagonist, but not aspirin, was effective in atherosclerosis inhibition in apo E-KO mice, showing that TP receptor blockade is affected by a mechanism independent of platelet derived thromboxane $\mathrm{A}_{2}$, , whereas isoprostane suppression with vitamin $\mathrm{E}$ retards atherogenesis in the same animal model. ${ }^{10}$ Similarly, another TP receptor antagonism (L670596), but not cyclooxygenase 2 (COX-2) inhibition, prevented pulmonary hypertension and endothelin-1 upregulation in $60 \% \mathrm{O}_{2}$ mediated pulmonary hypertension in newborn rats. ${ }^{11}$

To date, do we have sufficient evidence to conclude in favour of isoprostanes? Certainly not. Firstly, aside from prostaglandin $\mathrm{H}_{2}$-thromboxane $\mathrm{A}_{2}$ and isoprostanes, the TP receptors share other endogenous ligands such as HETE. One may reasonably suppose that other arachidonic acid derivatives will be discovered as endogenous TP receptor agonists in the future. Secondly, although unlikely, the candidate compound could be thromboxane $\mathrm{A}_{2}$ itself. Although aspirin given at $100 \mathrm{mg} /$ day completely inhibits platelet derived thromboxane $\mathrm{A}_{2}{ }^{12} \mathrm{COX}$ is expressed in all tissues, and one cannot rule out that endothelial cells may still be able to produce thromboxane $\mathrm{A}_{2}$, especially in CAD patients in whom the ability of endothelial cells to release prostacyclin is decreased.

\section{WHICH ISOPROSTANES ARE INVOLVED?}

An important challenge remains to determine which isoprostanes could be involved. Unlike prostaglandins, the non-specific free radical mechanism of their formation leads to 64 different isoprostanes for each isoprostane family, which mean hundreds of different compounds. Most attention was initially focused on $15-\mathrm{F}_{2 \mathrm{t}}$ isoprostane, which was the first commercially available isoprostane. The available data strongly suggest that the effects of $15-\mathrm{F}_{2 \mathrm{t}}$-isoprostane are mediated by the activation of the TP receptors acting as a full or partial agonist. ${ }^{13}$ Other isoprostanes belonging to the F-family, such as 9 epi-15$\mathrm{F}_{2 \mathrm{t}}$-isoprostane and 15 epi-15- $\mathrm{F}_{2 \mathrm{t}}$-isoprostane, are biologically active, although less potent, whereas 
5- $\mathrm{F}_{2 \mathrm{t}}$-isoprostane and its 5-epimer possess no vasomotor effects. ${ }^{14}{ }^{15}$ Aside from the F-family, isoprostanes with an E-ring are even more potent. ${ }^{16}$ Furthermore, Morrow and colleagues have shown that $\mathrm{A}_{2}$-isothromboxanes are formed in vivo. ${ }^{17}$ Because of the inherent instability of the thromboxane $\mathrm{A}_{2}$ ring, no research into the vascular effects of $\mathrm{A}_{2}$-isothromboxanes is available. However, considering the potency of thromboxane $\mathrm{A}_{2}$, $\mathrm{A}_{2}$-isothromboxanes are potentially interesting candidates.

In conclusion, the study by Nonaka-Sarukawa and colleagues further adds to our knowledge concerning the pathophysiological variations of isoprostanes in human cardiovascular physiology and disease. In the future we must try to determine whether these compounds are more than physiopathological biomarkers of lipid peroxidation. Considering we have no direct evidence, to date, concerning their involvement in the pathogenesis of cardiovascular diseases, we will still have to follow the fingerprints.

\section{REFERENCES}

1 Roberts LJ, Morrow JD. Measurement of $\mathrm{F}_{2}$-isoprostanes as an index of oxidative stress in vivo. Free Radic Biol Med 2000;28:505-13.

2 Morrow JD, Frei B, Longmire AW, et al. Increase in circulating products of lipid peroxidation ( $\mathrm{F}_{2}$-isoprostanes) in smokers. N Engl J Med 1995:332: 1 198-203.

3 Cracowski JL, Durand T, Bessard G. Isoprostanes as a biomarker of lipid peroxidation in humans: physiology, pharmacology and clinical implications. Trends Pharmacol Sci 2002;23:360-6.

4 Mallat Z, Philip I, Lebret $M$, et al. Elevated levels of 8-iso-prostaglandin $\mathrm{F}_{2 \alpha}$ in pericardial fluid of patients with heart failure: a potential role for in vivo oxidant stress in ventricular dilatation and progression to heart failure. Circulation 1998;97:1536-9.

5 Li H, Lawson JA, Reilly M, et al. Quantitative high performance liquid chromatography/tandem mass spectrometric analysis of the four classes of $\mathrm{F}(2)$-isoprostanes in human urine. Proc Natl Acad Sci USA

1999:96:13381-6.
6 Cracowski JL, Tremel F, Marpeau C, et al. Increased formation of $\mathrm{F}_{2}$-isoprostanes in patients with severe heart failure. Heart 2000;84:439-40.

7 Nonaka-Sarukawa M, Yamamoto K, Aoki H, et al. Increased urinary 15- $\mathrm{F}_{2-\mathrm{f}}$-isoprostane concentrations in patients with non-ischaemic congestive heart failure: a marker of oxidative stress. Heart 2003;89:871-4.

8 Belhassen L, Pelle G, Sediame S, et al. Improvement of endothelial function by TP-receptor antagonist S18886 in patients with coronary artery disease treated with aspirin. J Am Coll Cardiol (in press).

9 Cayatte AJ, Du Y, Oliver-Krasinski J, et al. The thromboxane receptor antagonist S18886 but not aspirin inhibits atherogenesis in apo E-deficient mice: evidence that eicosanoids other than thromboxane contribute to atherosclerosis. Arterioscler Thromb Vasc Biol 2000;20:1724-8

10 Pratico D, Tangirala RK, Rader DJ, et al. Vitamin E suppresses isoprostane generation in vivo and reduces atherosclerosis in ApoE-deficient mice. Nat Med 1998;4:1189-92.

11 Jankov RP, Belcastro R, Ovcina E, et al. Thromboxane A(2) receptors mediate pulmonary hypertension in $60 \%$ oxygen-exposed newborn rats by a cyclooxygenase-independent mechanism. Am J Respir Crit Care Med 2002; 166:208-14

12 Patrono C, Coller B, Dalen JE, et al. Platelet-active drugs: the relationships among dose, effectiveness, and side effects. Chest $2001 ; 119: 39$ S-63S.

13 Kinsella BT. Thromboxane A2 signalling in humans: a 'tail' of two receptors. Biochem Soc Trans 2001;29:641-54.

14 Cracowski JL, Devillier $\mathrm{P}$, Chavanon $\mathrm{O}$, et al. Isoprostaglandin $\mathrm{E}_{2}$ type III (8-iso-prostaglandin $E_{2}$ ) evoked contractions in human internal mammary artery. Life Sci 2001;68:2405-13.

15 Marlière $\mathrm{S}$, Cracowski JL, Durand $\mathrm{T}$, et al. The 5 -series $\mathrm{F}_{2}$-isoprostanes possess no vasomotor effects in the rat thoracic aorta, the human internal mammary artery and the human saphenous vein. $\mathrm{Br} J$ Pharmacol 2002; 135:1276-80.

16 Janssen LJ, Tazzeo T. Involvement of TP and EP3 receptors in vasoconstrictor responses to isoprostanes in pulmonary vasculature. J Pharmacol Exp Ther 2002;301:1060-6.

17 Morrow JD, Awad JA, Wu A, et al. Nonenzymatic free radical-catalyzed generation of thromboxane-like compounds (isothromboxanes) in vivo. J Biol Chem 1996;271:23185-90.

\section{IMAGES IN CARDIOLOGY}

\section{Myocardial bridge-like arterial graft compression by draining tube}

A patient with exertional angina and left main and two vessel coronary artery disease (left anterior descending and circumflex artery), with normal left ventricular function, underwent elective coronary artery bypass grafting, on extracorporeal circulation. The obtuse marginal branch was considered ungraftable, and a composite arterial graft (left internal mammary anastomosed to the radial artery) was inserted to the distal left anterior descending artery (LAD). After an uneventful operation the patient was transferred to the intensive care on intravenous glyceryl trinitrate. Five hours later, however, he developed ST elevation in leads I, aVL and V1-V5 and became hypotensive. He remained in cardiogenic shock despite systemic inotropes, intramammary papaverine, and intra-aortic balloon counterpulsation. Emergency angiography was performed revealing antegrade flow from the left main artery to the distal LAD. In addition, a moderate stenosis at the anastomosis between the mammary and the radial arteries, possibly as a result of vessel calibre mismatch, was noted, as well as angiographic appearance of systolic compression of the graft by a mediastinal draining tube (right, upper and lower panels). Angioplasty and stenting was performed at the anastomotic site between the mammary and the radial arteries, but despite the excellent angiographic result the ST elevation persisted. Subsequently, the draining tube was removed, resulting in immediate resolution of the ST elevations in the precordial and lateral leads. Left coronary artery angiography revealed cessation of antegrade filling to the distal LAD. The creatine phosphokinase peaked at $471 \mathrm{ng} / \mathrm{ml}$ the following day and echocardiography revealed a left ventricular ejection fraction of $60 \%$ with mild anteroapical hypokinesis. The ECG, before discharge on the 12th postoperative day, was remarkable for Q waves only in leads V1-V2.

E Sbarouni

Z S Kyriakides D Th Kremastinos elbee@ath.forthnet.gr

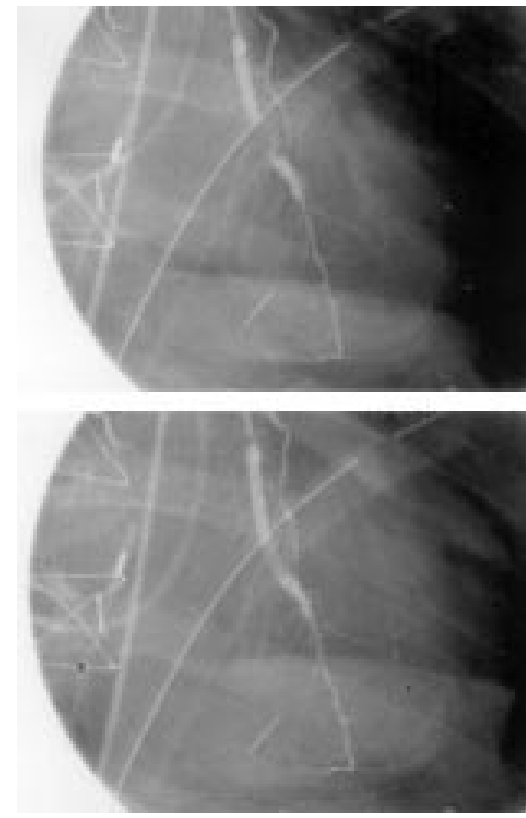

The draining tube crosses the course of the arterial graft in systole (upper panel) and diastole (lower panel), causing systolic compression. Proximal to the crossing point, a moderate stenosis at the anastomosis between the mammary and the radial arteries is also shown. 